\title{
Announcing a New Mayday Scholars Program
}

The American Society of Law, Medicine $\&$ Ethics announces a new research program in the area of legal, regulatory, and financing issues in pain relief with funding from the Mayday Fund of New York City. This program continues the Society's earlier efforts on Legal Constraints on Access to Effective Pain Relief, originally conducted in 1995-1997 and funded by the Mayday Fund and The Emily Davie and Joseph S. Kornfeld Foundation, and the Mayday Scholars Program funded by the Mayday Fund from 1997-1998. The program was continued in 1999-2000.

The earlier projects accomplished foundational research in legal issues relating to pain relief, including issues related to professional disciplinary actions, analyses for payment policies for pain management by Blue Cross/Blue Shield Associations and Medicare and Medicaid programs, an examination of criminal investigations and prosecutions of physicians and nurses for pain treatment at the end of life, research on whether undertreatment of pain should be grounds for disciplinary action by state medical boards, pain management in the era of managed care, expanding the role of pharmacists in pain management, sex and gender bias in the treatment of pain, and provider liability for failure to provide effective pain treatment. The Winter 1996 (26:4), Winter 1998 (28:4), and Spring 2001 (29:1) issues of the Journal of Law, Medicine \& Ethics are special issues devoted to the Mayday Scholars' research. Other information concerning the first project is available on the Society's web site at http://aslme.org/research/.

The newly funded project provides funds to expand scholarship and expertise in legal, regulatory, and financing policies that affect access to effective pain relief. The goal of the project is to broaden and deepen both the published scholarship specifically addressing aspects of the problem of undertreated pain and to increase the number of law, economics, and public policy scholars familiar with the specific context of pain relief in all types of healthcare delivery systems. Expanding the number of individuals with substantial research activity in the area will allow us to significantly expand opportunities for education, training, consultation, and media relations in this rather specialized area.

Mayday Scholars will undertake their own research projects. The Society will provide peer reviewers for the written product of the Scholars' projects. The Scholars will present their work at a Scholars' Workshop, which will be supported by the project.

The Society has identified the following topics as priorities; but candidates for the Scholars Program are encouraged to design their own projects as well:

- access to pain relief and Medicaid fraud and abuse;

- workers compensation and chronic pain;

- experience of boards of nursing in monitoring prescribing practices of advanced practice nurses;

- managed care and pain relief (including policies and payment issues relating to referrals, discharge, and choice of treatment); 
- treatment of pain in prisons;

- improving the investigation process of professional disciplinary agencies for prescribing practices related to pain management;

- pharmaceutical benefits management and the assessment of pain and discomfort; and

- specific institutional and regulatory contexts for pain management (e.g., nursing facilities, home care).

The Society will select four new Mayday Scholars. Funding for each Scholar's research will range from $\$ 6,000$ to $\$ 10,000$, and funds may be used for a stipend, research assistance, or general administrative support and supplies. Payment for general overhead is not available. It is anticipated that research funds will be disbursed through a contract for consultant's services for the Society and that reimbursement of expenses will be governed pursuant to that contract and in accordance with the requirements of the Mayday Fund and the Society's status as a tax-exempt organization. Each Scholar will also be supported for travel expenses associated with the Scholars' Workshop and will receive assistance in publication of the final product.

Applicants should submit the following: description of the proposed project (including statement of the problem and research strategy); description of the applicant's prior or current research and publications; curriculum vitae; and disclosure of financial support from or interest in related commercial entities.

Time Line for Mayday Scholars Program

- June 1, 2001: Application deadline

- July 1,2001: Selection and notification of scholars

- December 31,2001: Interim report due

- March 2002: Scholars workshop (St. Louis, Missouri)

- June 1, 2002: Article due

For further information, please contact Benjamin Moulton, Executive Director, American Society of Law, Medicine \& Ethics, 765 Commonwealth Avenue, Suite 1634, Boston, Massachusetts 02215, phone: 617-262-4990, fax: 617-437-7596, email: bmoulton@aslme.org; or Sandra Johnson, Office of the Provost, Saint Louis University, 221 N. Grand, DuBourg 106, St. Louis, Missouri 63108, phone: 314-977-3088, fax: 314977-3079, email: johnsosh@slu.edu. 